\title{
MEGACÓlON CHAGÁSICO ASSOCIADO A PNEUMATOSE CÍSTICA DIFUSA DO DELGADO E ÚLCERA PÉPTICA DUODENAL
}

\author{
CHAGASIC MEGACOLONASSOCIATED TO SMALL BOWEL DIFFUSE \\ PNEUMATOSIS AND DUODENAL PEPTIC ULCER
}

\author{
Mitre Kalil, TCBC-ES ${ }^{1}$ \\ Carlos Augusto Bergami Lima, RCBC-ES ${ }^{2}$ \\ Danilo Nagib Salomão Paulo, TCBC-ES ${ }^{3}$
}

\section{INTRODUÇÃO}

A pneumatose cística intestinal é uma doença de etiopatogenia ainda não bem esclarecida que cursa com lesões bolhosas sub-mucosas e/ou subserosas, acometendo em graus variáveis os intestinos delgado, grosso e mesos, sendo na maioria das vezes assintomática ${ }^{1}$.

A associação desta doença à imunossupressão, úlcera péptica, megacólon congênito, doença diverticular, RCUI e linfangioma é relatada na literatura com pouca frequência, porém, menos frequiente é ainda o acometimento simultâneo de três delas, o que motivou-nos à relatar este caso ${ }^{2}$.

\section{RELATO DO CASO}

Paciente de 63 anos, masculino, leucodérmico apresentou-se em nosso serviço com constipação intestinal crônica (até 30 dias sem evacuar), dor e distensão abdominal, plenitude pós-prandial, epigastralgia e náuseas. Foi submetido à retossigmoidoscopia e colonoscopia com biópsias, clister opaco e reação de Machado Guerreiro (positiva), tendo sido diagnosticado volumoso dólicomegassigmóide chagásico (Figura 1). A endoscopia digestiva alta mostrou uma úlcera duodenal em parede anterior que foi tratada durante seis meses. O paciente foi então internado, preparado e submetido à laparotomia, onde evidenciou-se múltiplas e difusas lesões bolhosas de tamanhos variados no jejuno e íleo (Figura 2) além do dólicomegassigmóide. Optamos pela retossigmoidectomia abdomino-perineal com abaixamento endo-anal do cólon pela técnica de CutaitTurnbull e biópsia excisional de uma pequena lesão cística do jejuno proximal para exame histopatológico.

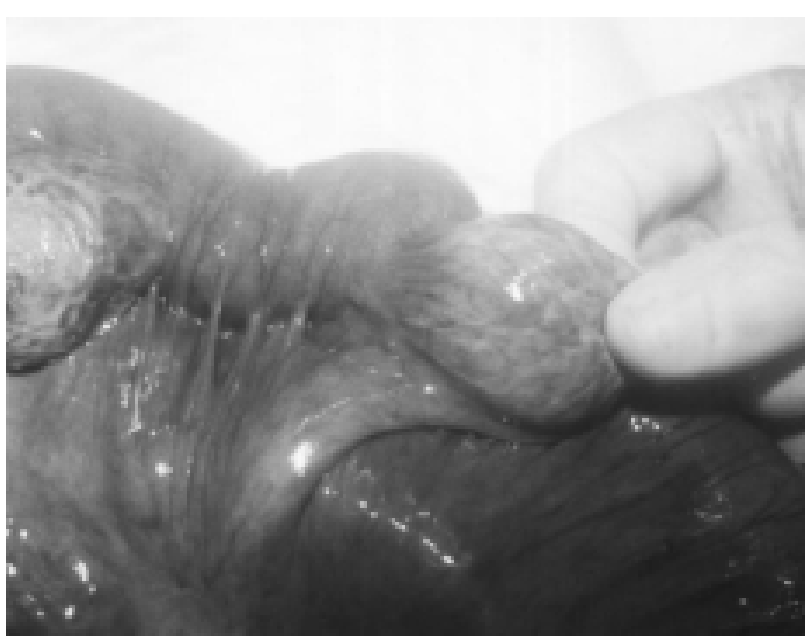

Figura 1

1. Professor Adjunto-Doutor da Disciplina de Técnica Operatória e Cirurgia Experimental; Chefe do Departamento de Clínica Cirúrgica e Coordenador do Internato em Clínica Cirúrgica da ESCSCMV-EMESCAM.

2. Residente em Cirurgia Geral da Santa Casa de Misericórdia de Vitória-E.Santo.

3. Professor Titular-Doutor da Disciplina de Técnica Operatória e Cirurgia Experimental e Coordenador do programa de Residência Médica em Cirurgia Geral da EMESCAM.

Recebido em 12/08/2002

Aceito para publicação em 06/01/2004

Trabalho realizado no Departamento de Clínica Cirúrgica da Escola Superior de Ciências da Santa Casa de Misericórdia de Vitória -E.Santo - EMESCAM. 


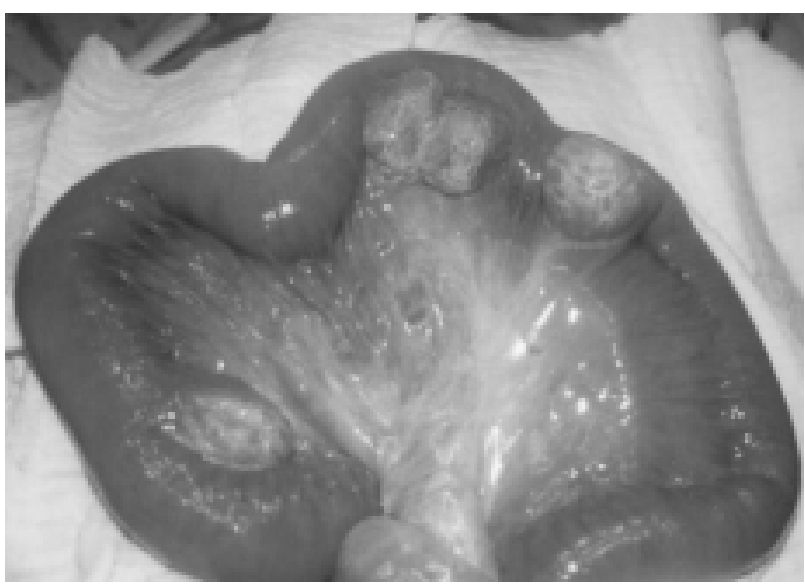

Figura 2

\section{DISCUSSÃO}

Embora na maioria dos pacientes seja assintomática, a presença da pneumatose cística do delgado (PCD) associada à outras doenças do trato gastrintestinal (TGI) faz com que seu diag- nóstico seja feito geralmente durante as laparotomias, exames necroscópicos, radiografias simples do abdome ou através do estudo contrastado do intestino delgado ${ }^{3}$. As lesões bolhosas podem ser solitárias ou confluentes, raramente evoluindo com contaminação bacteriana secundária e quando se rompem (pneumoperitônio estéril) fazem diagnóstico diferencial com úlcera péptica perfurada ${ }^{1 \cdot}$ Neste paciente a lesão péptica duodenal teve boa resposta ao tratamento clínico ao contrário da literatura, onde $60 \%$ das úlceras associadas à PCD são estenosantes ${ }^{4,5}$.

Outros aspectos que nos chamaram a atenção foram a faixa etária deste paciente e o megacólon chagásico, condições pouco freqüentes na literatura.Com relação ao predomínio de cistos no jejuno e sub-serosos, por nós verificados, condiz com os demais estudos. A conduta na maioria das vezes é conservadora, ficando as enterectomias segmentares, reservadas para aqueles casos que evoluem com obstrução intestinal, hemorragias e/ou perfurações ${ }^{1}$.

\begin{abstract}
Diffuse intestinal pneumatosis appears as gaseous cysts in the intestinal wall in the submucosal layer or, more frequently, sub-serous layer. It affects more the jejunum than the ileum, can be diffuse and may extend into the colon. It's diagnosis is established during a small bowel transit examination, necropsy examination or during surgical exploration of the peritoneal cavity.
\end{abstract}

Key Words: Pneumatosis cystoides intestinalis; Megacolon; Peptic ulcer cysts.

\section{REFERÊNCIAS}

1. Lázaro da Silva A - "Pneumatose cística intestinal". In Lázaro da Silva A - Cirurgia de urgência. $2^{a}$ Edição, Medsi,1994, pp. 267-268.

2. Gelman SF, Brandt LJ - Pneumatosis intestinalis and AIDS. a case report and review of literature. Am J Gastroenterol, 1998, 93(4):646-650.

3. Pear BL-Pneumatosis intestinalis: a review. Radiology, 1998, 207(1):13-19.

4. Koss LG - Abdominal gas cysts (pneumatosis cystoides intestinorum): an analysis with a report of a case and a critical review of literature. Arch Pathol, 1952,53:523-547.
5. Alves JB - "Pneumatose cística do intestino". In Cirurgia geral e especializada. Mec Veja, 1973, 7:629-630.

Endereço para correspondência:

DR. Mitre Kalil

Av. Antônio Gil Veloso, 1580/201, Praia da Costa

Vila Velha, Espírito Santo. CEP 29101-011

mitrecir@terra.com.br 